\title{
GIST: Sequencing Treatment and Case Report Evolution
}

\author{
Maria de Lourdes Lopes de Oliveira* \\ Oncology D'Or Department, Rio de Janeiro, South America
}

Submission: August 10, 2017; Published: August 24, 2017

*Corresponding author: Maria de Lourdes Lopes de Oliveira, Oncology D’Or Department, Rio de Janeiro 22271110, Brazil, Rua Sorocaba 464 / 408 . Botafogo. Rio de Janeiro, Brazil, South America, Tel: (+55 21)25378489; Fax: (+55 21) 999869125; Email: m.lourdes.oncologista@gmail.com

\begin{abstract}
Background: Gastrointestinal Stromal Tumor (GIST) is the most frequent mesenchymal tumor of the gastrointestinal tract; its most common site is the stomach (50-60\%), followed by small bowel (20-30\%), and large bowel (10\%), being less frequently found in the retroperitoneum, esophagus, omentum, and mesentery. Because in many cases this tumor shows a relatively slow growth rate and there is occurrence of clinically silent GISTs in up to $3 \%$ of autopsies, its true incidence is unknown. However, population-based studies conducted in various countries found estimated incidence rates varying between 6.6 and 14.5 per million people per year. Early case reports and clinical trials have established the role of the tyrosine-kinase inhibitor imatinib in inducing response and controlling the disease for variable periods of time. Given the sensitivity of advanced GIST to tyrosine-kinase inhibition, adjuvant therapy and a second line of tyrosine-kinase inhibitors have been developed, including sunitinib, regorafenib and other alternatives.
\end{abstract}

Case Presentation: Here we describe a 54 year-old male, presented with GIST who had the best response with each of the treatment lines and thus helped us understand the progress of GIST treatment as well as disease evolution.

Conclusion: This case report allowed us to describe the most salient aspects of the disease, having the practicing clinician in mind, while we also discuss recent options for the treatment of patients presenting disease progression after initial therapy with imatinib.

Keywords: (MeSH); GIST; Sarcoma; Tyrosine kinase

\section{Introduction}

Gastrointestinal Stromal Tumor (GIST) is the most frequent mesenchymal tumor of the gastrointestinal tract; its most common site is the stomach (50-60\%), followed by small bowel (20-30\%), and large bowel (10\%), being less frequently found in the retroperitoneum, esophagus, omentum, and mesentery [1-4]. Because in many cases this tumor shows a relatively slow growth rate and there is occurrence of clinically silent GISTs in up to $3 \%$ of autopsies [5] its true incidence is unknown. It has been estimated that approximately 5,000 new cases of GIST are diagnosed each year in the US alone [6]. No data are currently available regarding the epidemiology of GIST in Brazil, but there has been growing interest in this disease on the part of clinicians and investigators over the years.

KIT expression is a major diagnostic criterion for GIST, and nearly 95\% of GIST tumors stain positively for CD117 [6]. In most cases, somatic KIT mutations can be found, typically in exons 9, 11, and 13 [6,7]. In the largest published series of patients from Brazil, the immunohistochemical and mutation profiles of GIST were similar to those previously reported [8]. When no KIT mutations are found, sometimes a somatic mutation is found instead in the gene encoding the plateletderived growth-factor receptor (PDGFR) $[9,10]$. Since PDGFR is structurally closely related to KIT, both have become targets for similar therapeutic interventions, which is further discussed in detail. GISTs may also stain positively for CD34 and smoothmuscle actin, and are generally negative for desmin and S-100 expression. A diagnostic panel including these markers usually differentiates between GIST and other soft-tissue tumors $[6,11]$. However, it should be noted that marker expression in GIST may vary according to tumor location [11].

Over the years, various stratification schemes have been proposed for GIST patients, and they appear to have overall equivalent prognostic accuracies [12]. A consensus meeting in 2001 emphasized tumor size and mitotic index for risk stratification of primary GIST [1]. According to these guidelines, a high-risk primary GIST is defined as a tumor that either (1) measures $>10 \mathrm{~cm},(2)$ has a mitotic count $>10$ (per 50 highpower fields), or (3) has a mitotic count $>5$ and size is $>5$ $\mathrm{cm}$. Intermediate-risk GIST is defined as a tumor that either (1) measures $<5 \mathrm{~cm}$ and has a mitotic count of 6 to 10 , or (2) 
measures from 5 to $10 \mathrm{~cm}$ and has a mitotic count $<5$. Low-risk lesions measure between 2 and $5 \mathrm{~cm}$ and have mitotic counts $<5$, and very-low-risk lesions measure $<2 \mathrm{~cm}$ and have mitotic counts $<5$. Given the variable risk of recurrence according to the primary site of GIST, patient stratification may also take into account the lesion site $[13,14]$. For intestinal GISTs, tumor size $>5 \mathrm{~cm}$, regardless of the mitotic index, indicates at least a moderate risk for metastasis, and a mitotic count $>5$ denotes a high risk; intestinal GISTs that measure $\leq 5 \mathrm{~cm}$ and have mitotic counts $\leq 5$ have a low risk for metastases [13].

Apart from asymptomatic lesions measuring $<2 \mathrm{~cm}$, surgical resection is the mainstay of therapy for primary GIST with no metastasis in order to reach complete resection of visible and microscopic disease, avoid tumor rupture and obtain negative margins $[15,16]$. Patients with a gastric primary tumor do better than those with intestinal primary tumors. GIST has a tendency to recur both locally and in the form of peritoneal and liver metastases, but lymph-node and distant metastases are infrequent [6]. As for asymptomatic GISTs measuring <2 $\mathrm{cm}$, there is insufficient information to guide its management, which are often discovered incidentally on endoscopy. Systemic therapy for GIST may be used for patients with advanced disease or in the adjuvant and neoadjuvant settings. Early case reports and clinical trials have established the role of the tyrosine-kinase inhibitor imatinib in inducing response and controlling the disease for variable periods of time $[17,18]$. Given the sensitivity of advanced GIST to tyrosine-kinase inhibition, adjuvant therapy and a second and third line of tyrosine-kinase inhibitor to treatment is the new reality.

Since 2001, the introduction of imatinib radically improved the survival of patients with GIST; however, $12-15 \%$ of patients are primarily resistant to this agent, [19] and most eventually develop secondary resistance. Moreover, some patients can be intolerant to imatinib. For patients who are refractory or intolerant to imatinib, alternative treatments have emerged as options in second and subsequent lines of therapy. Sunitinib is a multi-targeted tyrosine-kinase inhibitor approved by the US Food and Drug Administration for patients with GIST-resistant or who are intolerant to imatinib. Its clinical benefit was demonstrated in a pivotal trial of sunitinib versus placebo in 312 patients with refractory disease [20]. In 2011, Regorafenib emerged as a novel multi-kinase inhibitor with activity against multiple targets, including vascular endothelial growth factor receptors 1-3, PDGFR, fibroblast growth factor receptor 1, Kit, and other protein kinases [21]. Here we present a case of a patient with GIST who underwent different treatment strategies and received different choices of tyrosine-kinase inhibition, adjuvant therapy and a second and third line of tyrosine-kinase inhibition that in total provided an overall survive of 13 years.

\section{Case Presentation}

A 54 year-old male, engineer, presented with an abdominal mass in November of 2002, at a private hospital in Rio de Janeiro,
Brazil. Family history indicated occurrence of several previous cases of cancer in the family, including of lung, uterus, colon and kidney cancer. The patient was submitted to an abdominal laparoscopy that revealed an ileum tumor with pelvic metastases. The main tumor was resected, with macroscopically residual disease. Histopathological analysis of the main tumor showed an $11 \times 7 \mathrm{~cm}$ lesion in the ileum, and fragments in the peritoneum of $2.5 \times 1.0 \mathrm{~cm}$, both suggestive of gastrointestinal stromal tumor (GIST). To confirm the GIST, an immunohistochemistry staining was done revealing diffuse cytoplasmic positivity for CD 117 (c-KIT).

In the post-operative physical examination, the patient presented adequate performance status (PS 1) and the physical examination revealed a mesogastric abdominal mass. The medical team decided to start imatinib using the standard recommended dose of $400 \mathrm{mg} /$ day. This treatment was initiated in November of 2002. The patient was well for 5 years, and continued to use the medication as expected and according to the findings of a pivotal phase III trial of imatinib in metastatic GIST. During follow-up, CT images obtained at every six months showed a progressive decrease of the tumors until 2007 when the tumors were no longer detected. In 2009 and after 7 years of taking $400 \mathrm{mg} /$ day of imatinib, several mesenteric nodules and a retrovesical mass were shown in the CT images. The imatinib dose was then increased to $800 \mathrm{mg}$ /day as a second line treatment for progressive disease. The patient started the new dose in 2009 but in August 2010, he developed adverse events and was hospitalized with dehydration, diarrhea, malnutrition and hypoalbuminemia.

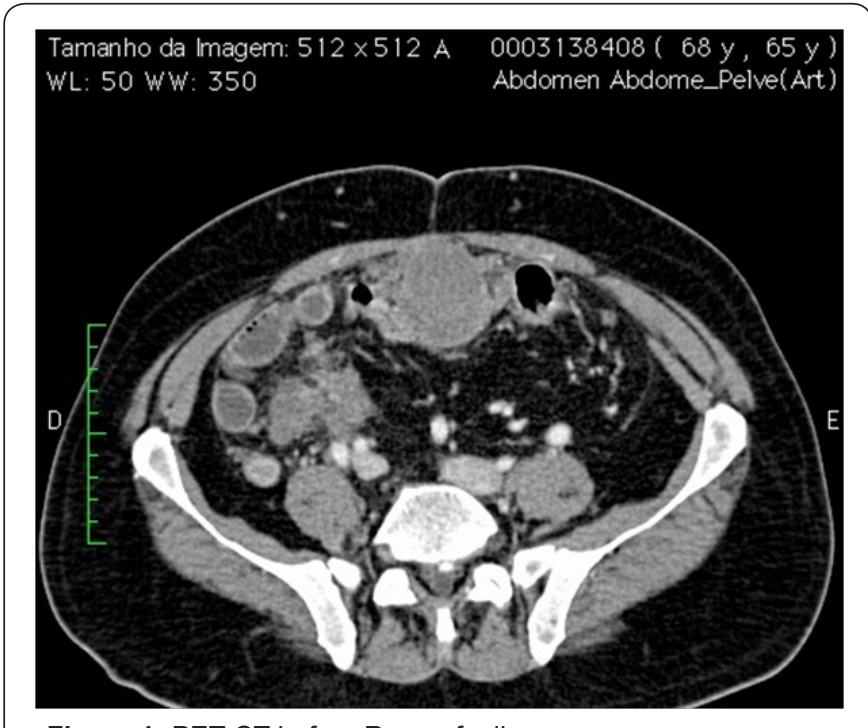

Figure 1: PET-CT before Regorafenib.

Therefore, the imatinib was interrupted and the patient was off of similar medication for five months. In January 2011, after several months of hospitalization, the patient returned for evaluation and a CT image revealed disease progression. The patient started to take $25 \mathrm{mg} /$ day of sunitinib and one month later, the dose increased to $50 \mathrm{mg} /$ day for 4 weeks on and 2 weeks 
off treatment, with good response and mild and manageable side effects, namely diarrhea, periorbital edema and elevated TSH. The patient showed stable disease for 30 months, which is a period longer than the average time period of phase III trial of sunitinib for GIST patients after progression of imatinib. In August 2013, a PET CT showed the disease had progressed to lymph nodes and the patient complained of abdominal pain (Figure 1).

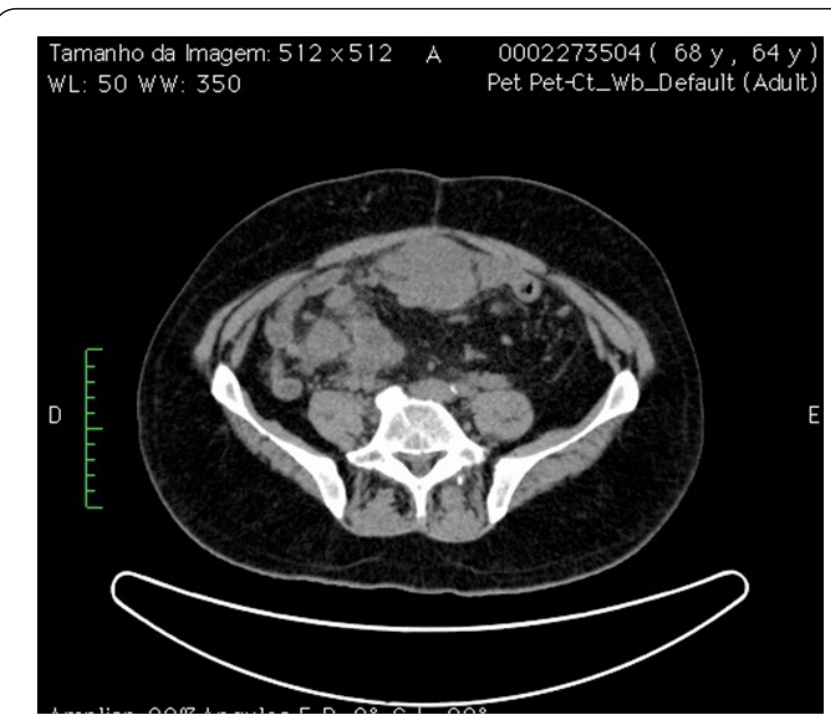

Figure 2: PET-CT after 5 months of regorafenibe.

At that time, Regorafenib was started as a third line treatment at $160 \mathrm{mg} /$ day for 21 days with 7 days off, following the protocol used in the trial for regorafenib in GIST, which referred the medication as third line treatment for cases where disease progression was observed following the intake of imatinib and then of sunitinib. The patient presented stable disease for 18 months (Figure 2) and until February 2015, when a PET CT showed disease progression. During the 18-month period while taking regorafenib, the patient presented with good performance status (PS 1) and tolerated well adverse events. The most important toxicity was diarrhea and asthenia, both grades 2 . This great response exceeded expectations, according to median time of progression-free survival observed in a phase III pivotal study [22].

At the time of progression while taking regorafenib, patient's performance status was still 1. Imatinib reintroduction was considered but, after 3 months of intake of reduced dose (400mg/day), patient's performance status declined, and the abdominal mass became symptomatic and pazopanib was planned to be introduced. The patient died in November 2015 before starting the pazopanib treatment.

\section{Discussion}

Objective responses to imatinib, which are typically partial, is expected in approximately two-thirds of patients, and the median progression-free survival ranges from 15 to 20 months. Imatinib interruption, or discontinuation, has generated significant controversy over the years. A randomized trial has shown that a high risk of rapid progression exists even when the agent is discontinued after 3 years, thus suggesting that discontinuation of imatinib in responding patients with good tolerance should not be done outside clinical trials [23]. Despite early controversies regarding the initial use of higher doses, a daily dose of $400 \mathrm{mg}$ is standard for most patients, and higher doses (600 or $800 \mathrm{mg}$ daily, as tolerated) may be considered for patients with disease progression or specific mutations (e.g., KIT exon 9 mutations) [15,24]. Although there is clear value in monitoring imatinib serum levels, it should not be done routinely [15]. Surgical resection of residual disease among patients who are responding to imatinib may be considered in selected cases, although only an inconclusive randomized trial that investigated the issue has been published so far [25].

Finally, retreatment with imatinib is feasible for some patients with a planned discontinuation, but the benefit thus achieved and the availability of novel agents have not encouraged the option as a routine practice [26,27]. It should be noted that imatinib is extensively metabolized by the CYP3A4 enzyme, thus having the potential to interact with various drugs [28]. Moreover, imatinib has the potential to increase the concentration of drugs such as warfarin and midazolam. Fluid retention, dyspepsia, nausea, diarrhea, fatigue, muscle cramps, abdominal pain, and rash are the most common adverse events reported with imatinib, whereas lung toxicity, liver function abnormalities, leukopenia and gastrointestinal bleeding are relatively rare [29].

Although the optimum duration of imatinib adjuvant treatment is not yet known, postoperative imatinib is recommended for at least 12 months in intermediate- to highrisk patients [15]. Of note, a randomized trial showed improved relapse-free and overall survival for 3 years of adjuvant therapy with imatinib, in comparison with only 12 months, among patients with a high risk of recurrence [30]. Imatinib as neoadjuvant therapy is supported by previous studies [31] for patients with large primary tumors that are potentially resectable, in whom downstaging may allow for potentially curative surgery $[15,32]$. However, the use of imatinib as neodjuvant therapy has been reported in small clinical trials only, with no concurrent comparison of the results obtained with immediate surgery [3336]. Given the results of randomized trials on adjuvant therapy, postoperative imatinib should be considered for patients undergoing preoperative therapy.

Sunitinib is a multi-targeted tyrosine-kinase inhibitor approved by the US Food and Drug Administration for patients with GIST resistant or intolerant to imatinib. In the latest update, in a pivotal trial of sunitinib versus placebo in patients with refractory disease, [20] the objective response of patients in the sunitinib group was only $7 \%$; however, the median time to tumor progression was significantly higher in this group than in the placebo group (27 versus 6 weeks; hazard 
ratio $[\mathrm{HR}]=0.33 ; \mathrm{p}<0.0001)$. In the initial report, there was a significant difference in overall survival favoring sunitinib, but crossover design allowed all patients the opportunity to benefit from access to this active treatment and likely contributed to a lack of significant difference in the final analysis [37]. The main adverse events with sunitinib include anemia, neutropenia, fatigue, diarrhea, skin discoloration, nausea, anorexia, dysgeusia, stomatitis, and vomiting. Most adverse events are manageable with symptomatic, periodic interruptions, or dose reduction. The approved dose is $50 \mathrm{mg}$ daily for 4 of every 6 weeks, but an alternative schedule of continuous daily intake of $37.5 \mathrm{mg}$ has indications to be safe and effective [38].

The activity of regorafenib, a multi-kinase inhibitor that acts against multiple targets, including vascular endothelial growth factor receptors 1-3 (VEGFR), platelet-derived growth factor receptor (PDGFR), fibroblast growth factor receptor 1 (FGFR), KIT, and other protein kinases, also acts against GIST cell lines, which was demonstrated in preclinical studies $[21,39]$. A subsequent phase II trial of regorafenib in patients with advanced GIST after failure of both imatinib and sunitinib demonstrated a median progression-free survival of 10 months [40]. Partial response and stable disease for 16 weeks or longer were reported in four and in 22 patients, respectively. These promising results prompted the GIST-Regorafenib In progressive Disease (GRID) phase III trial, in which 199 patients with metastatic or unresectable GIST refractory to imatinib or sunitinib were randomized to receive regorafenib or placebo [22].

The median progression-free survival was 4.8 months in the regorafenib arm and 0.9 month in the placebo arm (HR=0.27; $\mathrm{p}<0.0001)$. Partial response was uncommon and occurred in six patients in the regorafenib arm and in one patient in the placebo arm. On the other hand, stable disease was achieved in $71 \%$ of patients in the regorafenib group and in $33 \%$ of patients in the placebo group ( $\mathrm{p}<0.0001)$. Like other effective kinase inhibitors in TKI-resistant disease, regorafenib did not induce high rates of objective tumor response, according to modified RECIST criteria [22]. However, disease control rate (defined as the sum of objective tumor response plus stable disease for at least 12 weeks) was higher in regorafenib-treated patients $(52.6 \%$, $70 / 133$ patients) than in placebo-receiving patients $(9.1 \%$, $6 / 66$ patients), suggesting that regorafenib was associated with clinically meaningful tumor control in patients with advanced GIST following failure of all other approved TKI therapies.

The benefit of regorafenib was observed both for patients whose tumors harbored exon 11 and exon 9 mutations. The only group in which the benefit of regorafenib was not identified was in the small subset of patients with less than 6 months of imatinib treatment. There was a significant benefit with the use of regorafenib even among the $43 \%$ of patients who had received three or more previous lines of anticancer therapy for GIST. There was no difference in overall survival between groups, probably because of crossover in $85 \%$ of the patients from the placebo group after progression. Such impression is confirmed by a recent exploratory analysis, in which statistical adjustment for the effect of crossover during the GRID trial disclosed a benefit in overall survival favoring regorafenib [41].

Final overall survival analysis with modeling of crossover impact in the phase III GRID trial of regorafenib versus placebo in advanced gastrointestinal stromal tumors (GIST) showed that IPE correction provides more linearly median times and overall survival hazard ratios than RPSFT. These exploratory analyses modeling the impact of crossover to active drug suggest that regorafenib has a greater overall survival benefit than noted in the intention-to-treat analyses (HR=0.51; IC 0.35-0.73) [41]. These results led to the approval of regorafenib by the US Food and Drug Administration for the treatment of metastatic or unresectable GIST after progression with imatinib and sunitinib.

The most common grade 3 or higher adverse events related to regorafenib in the GRID trial were hypertension, handfoot syndrome, and diarrhea [22]. However, nearly the same percentage of patients in the regorafenib $(6 \%)$ and placebo $(8 \%)$ arms required permanent discontinuation of the study drug due to adverse events, which suggests that the toxicity of regorafenib may be adequately managed with dose modification. Handfoot syndrome may be a bothersome adverse event of various anticancer agents, including some tyrosine-kinase inhibitors. Among the proposed strategies to mitigate this adverse event caused by regorafenib are close patient monitoring, avoidance of skin pressure or trauma, topical emollient therapy, and reducing the dose of the medication [42]. Fatigue is also a frequent finding among these patients, but the extent to which it is due to treatment or the disease itself may not always be evident. In the GRID trial, fatigue was reported in $39 \%$ of patients treated with regorafenib (grade 3 in only 2\%), and $27 \%$ of those receiving placebo (no cases of grade 3) [22]. These toxicities do not appear to be cumulative, and patient education and monitoring, as well as proactive management, are key components of a strategy to reduce their incidence, duration, and severity [42].

\section{Other Tyrosine-Kinase Inhibitors}

Nilotinib is a potent second-generation tyrosine- kinase inhibitor with activity against cell lines with activating mutations of Kit or PDGFR [43,44]. Moreover, nilotinib has antitumor effect against GIST cell lines and imatinib-resistant GIST patients $[45,46]$. A phase II trial evaluated nilotinib in 35 patients who were resistant or intolerant to both imatinib and sunitinib [47]. Nine patients achieved stable disease as the best response at week 24 , and only one patient had partial response. Other studies supported the clinical activity of nilotinibfollowing prior imatinib and sunitinib failure $[48,49]$. However, a large randomized trial comparing nilotinib versus best supportive care failed to demonstrate clinical benefit by central review among patients with GIST refractory or intolerant to both 
imatinib and sunitinib [50]. Finally, a randomized trial compared nilotinib versus imatinib as first-line treatment for advanced GIST, but no significant activity was demonstrated in this setting [51]. Therefore, nilotinib warrants further evaluation before being incorporated into clinical practice for GIST therapy [52].

Sorafenibis another multi-targeted inhibitor with selectivity to angiogenic kinases and the GIST oncogenic drivers, Kit and PDGFR. Its antitumor activity against imatinib- and sunitinibresistant GIST cell models was demonstrated in preclinical studies [53]. In a phase II trial, sorafenib was administered to 31 patients with pretreated GIST and showed $36 \%$ of disease control rate, defined as partial response or stable disease at 24 weeks [54]. In another phase II trial that evaluated sorafenib for patients with unresectable tumor, KIT-positive GIST refractory to imatinib and sunitinib, 55\% of patients had stable disease, and $13 \%$ had partial responses [55]. Retrospective studies reported the activity of sorafenib in GIST resistant to imatinib and sunitinib [56,57].

Dasatinib, which has activity against mutant Kit and PDGFR, [58] was assessed in two phase II trials in GIST. In one trial, 47 patients with GIST resistant to imatinib and sunitinb were treated; despite the fact that $32 \%$ of patients had a partial response and $21 \%$ were progression-free for at least 6 months, these results did not meet the predefined efficacy criterion [59]. In a phase II trial among kinase-naïve patients, dasatinib led to metabolic responses at 4 weeks in $67 \%$ of patients and a median progression-free survival of 11 months [60]. Masitinib is a novel tyrosine-kinase inhibitor that potently inhibits wild-type and exon 11 mutant Kit, with antitumor activity in patients with GIST resistant to imatinib [61]. It also showed activity in a phase II trial that enrolled 30 imatinib-naïve patients [62]. Disease control was achieved in $96.7 \%$ of patients, with a median progressionfree survival of 41 months. Two randomized trials are comparing masitinib versus standard therapies in first and second lines of treatment $[63,64]$. Finally, pazopanib, motesanib and vatalanib are tyrosine-kinase inhibitors that target Kit, VEGFR and PDGFR, but they had only modest activity in GIST [65-67].

\section{Conclusion}

Despite the benefit from the use of imatinib, most patients with GIST acquire resistance to this agent. Importantly, oncogenic kinase activity continues to be crucial for tumor cell proliferation and survival after disease progression [68]. Sunitinib and regorafenibhave expanded the therapeutic arsenal in GIST, as they provide clinical benefit for patients with GIST in second and third lines of therapy, respectively [22,37]. Regorafenib is a multi-kinase inhibitor with a manageable safety profile and demonstrated benefit in terms of progression-free survival for patients with the most frequent KIT mutations [22]. The introduction of regorafenib is a welcome expansion of the treatment arsenal against GIST and gives patients an even broader therapeutic horizon than only a few years ago. Despite the improved survival accrued from the use of such therapies over the past 15 years, patients still require effective novel agents, many of which are under investigation. It is hoped that continuing improvements in drug development and better understanding of the clinical implications of genotypic alterations will allow for further gains for patients with GIST.

\section{Acknowledgment}

This research did not receive any specific grant from funding agencies in the public, commercial, or not-for-profit sectors.

\section{References}

1. Fletcher CD, Berman JJ, Corless C (2002) Diagnosis of gastrointestinal stromal tumors: A consensus approach. Hum Pathol 33: 459-465.

2. Lv M, Wu C, Zheng Y, Zhao N (2014) Incidence and survival analysis of gastrointestinal stromal tumors in shanghai: a population-based study from 2001 to 2010. Gastroenterol Res Pract 2014: 834136.

3. Tryggvason G, Kristmundsson T, Orvar K, Jonasson JG, Magnusson MK, et al. (2007) Clinical study on gastrointestinal stromal tumors (GIST) in Iceland, 1990-2003. Dig Dis Sci 52: 2249-2253.

4. Chiang NJ, Chen LT, Tsai CR, Chang JS (2014) The epidemiology of gastrointestinal stromal tumors in Taiwan, 1998-2008: a nation-wide cancer registry-based study. BMC Cancer 14:102.

5. Muenst S, Thies S, Went P, Tornillo L, Bihl MP, et al. (2011) Frequency, phenotype, and genotype of minute gastrointestinal stromal tumors in the stomach: an autopsy study. Hum Pathol 42: 1849-1854.

6. Corless CL, Fletcher JA, Heinrich MC (2004) Biology of gastrointestinal stromal tumors. J Clin Oncol 22: 3813-3825.

7. Hirota S, Isozaki K, Moriyama Y (1998) Gain-of-function mutations of c-kit in human gastrointestinal stromal tumors. Science 279: 577-580.

8. Lopes LF, Ojopi EB, Bacchi CE (2008) Gastrointestinal stromal tumor in Brazil: clinicopathology, immunohistochemistry, and molecular genetics of 513 cases. Pathol Int 58: 344-352.

9. Heinrich MC, Corless CL, Duensing A (2003) PDGFRA activating mutations in gastrointestinal stromal tumors. Science 299: 708-710.

10. Hirota S, Ohashi A, Nishida T (2003) Gain-of-function mutations of platelet-derived growth factor receptor alpha gene in gastrointestinal stromal tumors. Gastroenterology 125: 660-667.

11. Miettinen M, Sobin LH, Sarlomo-Rikala M (2000) Immunohistochemical spectrum of GISTs at different sites and their differential diagnosis with a reference to CD117 (KIT). Mod Pathol 13: 1134-1142.

12. Joensuu H, Vehtari A, Riihimaki J (2012) Risk of recurrence of gastrointestinal stromal tumour after surgery: an analysis of pooled population-based cohorts. Lancet Oncol 13: 265-274.

13. Miettinen M, Lasota J (2006) Gastrointestinal stromal tumors: pathology and prognosis at different sites. SeminDiagnPathol 23: 7083.

14. Gold JS, Gonen M, Gutierrez A (2009) Development and validation of a prognostic nomogram for recurrence-free survival after complete surgical resection of localised primary gastrointestinal stromal tumour: a retrospective analysis. Lancet Oncol 10: 1045-1052.

15. Demetri GD, von Mehren M, Antonescu CR (2010) NCCN Task Force report: update on the management of patients with gastrointestinal stromal tumors. J Natl Compr Canc Netw 8(Suppl 2): S1-41. 


\section{Open Access Journal of Surgery}

16. Blay JY, Bonvalot S, Casali P (2005) Consensus meeting for the management of gastrointestinal stromal tumors. Report of the GIST Consensus Conference of 20-21 March 2004, under the auspices of ESMO. Ann Oncol 16: 566-578.

17. Demetri GD, von Mehren M, Blanke CD (2002) Efficacy and safety of imatinibmesylate in advanced gastrointestinal stromal tumors. N Engl J Med 347: 472-480.

18. Verweij J, Casali PG, Zalcberg J (2004) Progression-free survival in gastrointestinal stromal tumours with high-dose imatinib: randomised trial. Lancet 364: 1127-1134.

19. Van Glabbeke M, Verweij J, Casali PG (2005) Initial and late resistance to imatinib in advanced gastrointestinal stromal tumors are predicted by different prognostic factors: a European Organisation for Research and Treatment of Cancer-Italian Sarcoma Group-Australasian Gastrointestinal Trials Group study. J ClinOncol 23: 5795-5804.

20. Demetri GD, Garrett CR, Schoffski P (2012) Complete longitudinal analyses of the randomized, placebo-controlled, phase III trial of sunitinib in patients with gastrointestinal stromal tumor following imatinib failure. Clin Cancer Res 18: 3170-3179.

21. Wilhelm SM, Dumas J, Adnane L (2011) Regorafenib (BAY 73-4506): a new oral multikinase inhibitor of angiogenic, stromal and oncogenic receptor tyrosine kinases with potent preclinical antitumor activity. Int J Cancer 129: 245-255.

22. Demetri GD, Reichardt P, Kang YK (2013) Efficacy and safety of regorafenib for advanced gastrointestinal stromal tumours after failure of imatinib and sunitinib (GRID): an international, multicentre, randomised, placebo-controlled, phase 3 trial. Lancet 381: 295-302.

23. LeCesne A, Ray-Coquard I, Bui BN (2010) Discontinuation of imatinib in patients with advanced gastrointestinal stromal tumours after 3 years of treatment: an open-label multicentre randomised phase 3 trial. Lancet Oncol 11: 942-949.

24. Debiec-Rychter M, Sciot R, Le Cesne A (2006) KIT mutations and dose selection for imatinib in patients with advanced gastrointestinal stromal tumours. Eur J Cancer 42: 1093-1103.

25. Du CY, Zhou Y, Song C (2014) Is there a role of surgery in patients with recurrent or metastatic gastrointestinal stromal tumours responding to imatinib: a prospective randomised trial in China. Eur J Cancer 50: 1772-1778.

26. Patrikidou A, Chabaud S, Ray-Coquard I (2013) Influence of imatinib interruption and rechallenge on the residual disease in patients with advanced GIST: results of the BFR14 prospective French Sarcoma Group randomised, phase III trial. Ann Oncol 24: 1087-1093.

27. Kang YK, Ryu MH, Yoo C (2013) Resumption of imatinib to control metastatic or unresectable gastrointestinal stromal tumours after failure of imatinib and sunitinib (RIGHT): a randomised, placebocontrolled, phase 3 trial. Lancet Oncol 14: 1175-1182.

28. Mucciarini C, Rossi G, Bertolini F (2007) Incidence and clinicopathologic features of gastrointestinal stromal tumors. A population-based study. BMC Cancer 7: 230

29. Komatsu Y, Doi T, Sawaki A (2015) Regorafenib for advanced gastrointestinal stromal tumors following imatinib and sunitinib treatment: a subgroup analysis evaluating Japanese patients in the phase III GRID trial. Int J ClinOncol 20(5): 905-912.

30. Joensuu H, Eriksson M, Sundby Hall K (2012) One vs three years of adjuvant imatinib for operable gastrointestinal stromal tumor: a randomized trial. JAMA 307: 1265-1272.

31. Ramaswamy A, Jain D, Sahu A (2016) Neoadjuvant imatinib: longer the better, need to modify risk stratification for adjuvant imatinib. J Gastrointest Oncol 7(4): 624-631.

32. (2012) Gastrointestinal stromal tumors: ESMO Clinical Practice Guidelines for diagnosis, treatment and follow-up. Ann Oncol 23(Suppl
7): vii49-55.

33. Rutkowski P, Gronchi A, Hohenberger P (2013) Neoadjuvant imatinib in locally advanced gastrointestinal stromal tumors (GIST): the EORTC STBSG experience. Ann SurgOncol 20: 2937-2943.

34. Tielen R, Verhoef C, van Coevorden F (2013) Surgical treatment of locally advanced, non-metastatic, gastrointestinal stromal tumours after treatment with imatinib. Eur J SurgOncol 39: 150-155.

35. Blesius A, Cassier PA, Bertucci F (2011) Neoadjuvant imatinib in patients with locally advanced non metastatic GIST in the prospective BFR14 trial. BMC Cancer 11: 72.

36. Eisenberg BL, Harris J, Blanke CD (2009) Phase II trial of neoadjuvant/ adjuvant imatinibmesylate (IM) for advanced primary and metastatic/ recurrent operable gastrointestinal stromal tumor (GIST): early results of RTOG 0132/ACRIN 6665. J Surg Oncol 99: 42-47.

37. Demetri GD, van Oosterom AT, Garrett CR (2006) Efficacy and safety of sunitinib in patients with advanced gastrointestinal stromal tumour after failure of imatinib: a randomised controlled trial. Lancet 368 : 1329-1338.

38. George S, Blay JY, Casali PG (2009) Clinical evaluation of continuous daily dosing of sunitinib malate in patients with advanced gastrointestinal stromal tumour after imatinib failure. Eur J Cancer 45: 1959-1968.

39. Fletcher JA, Rubin BP (2007) KIT mutations in GIST. CurrOpin Genet Dev 17: 3-7.

40. George S, Wang Q, Heinrich MC (2013) Efficacy and safety of regorafenib in patients with metastatic and/or unresectable G stromal tumor after failure of imatinib and sunitinib: a multicenter phase II trial. J ClinOncol 30: 2401-2407.

41. Demetri GD, Reichardt P, Kang YK, Blay JY, Joensuu H, et al. (2015) An updated overall survival analysis with correction for protocol-planned crossover of the international, phase III, randomized, placebocontrolled trial of regorafenib in advanced gastrointestinal stromal tumors after failure of imatinib and sunitinib (GRID). J ClinOncol 33(suppl 3).

42. De Wit M, Boers-Doets CB, Saettini A (2014) Prevention and management of adverse events related to regorafenib. Support Care Cancer 22: 837-846.

43. Weisberg E, Manley PW, Breitenstein W (2005) Characterization of AMN107, a selective inhibitor of native and mutant Bcr-Abl. Cancer Cell 7: 129-141.

44. Manley PW, Drueckes P, Fendrich G (2010) Extended kinase profile and properties of the protein kinase inhibitor nilotinib. Biochim Biophys Acta 1804: 445-453.

45. Sako H, Fukuda K, Saikawa Y (2014) Antitumor effect of the tyrosine kinase inhibitor nilotinib on gastrointestinal stromal tumor (GIST) and imatinib-resistant GIST cells. PloSOne 9: e107613.

46. Demetri GD, Casali PG, Blay JY (2009) A phase I study of single-agent nilotinib or in combination with imatinib in patients with imatinibresistant gastrointestinal stromal tumors. Clin Cancer Res 15: 59105916

47. Sawaki A, Nishida T, Doi T (2011) Phase 2 study of nilotinib as thirdline therapy for patients with gastrointestinal stromal tumor. Cancer 117: 4633-4641.

48. Montemurro M, Schoffski P, Reichardt P (2009) Nilotinib in the treatment of advanced gastrointestinal stromal tumours resistant to both imatinib and sunitinib. Eur J Cancer 45: 2293-2297.

49. Cauchi C, Somaiah N, Engstrom PF (2012) Evaluation of nilotinib in advanced GIST previously treated with imatinib and sunitinib. Cancer Chemother Pharmacol 69: 977-982. 
50. Reichardt P, Blay JY, Gelderblom H (2012) Phase III study of nilotinib versus best supportive care with or without a TKI in patients with gastrointestinal stromal tumors resistant to or intolerant of imatinib and sunitinib. Ann Oncol 23: 1680-1687.

51. Blay JY, Shen L, Kang YK, Rutkowski P (2013) Phase III trial of nilotinib versus imatinib as first-line targeted therapy of advanced gastrointestinal stromal tumors (GIST). J ClinOncol.

52. Kanda T, Ishikawa T, Takahashi T, Nishida T (2013) Nilotinib for treatment of gastrointestinal stromal tumors: out of the equation? Expert Opin Pharmacother 14: 1859-1867.

53. Heinrich MC, Marino-Enriquez A, Presnell A (2012) Sorafenib inhibits many kinase mutations associated with drug-resistant gastrointestinal stromal tumors. Mol Cancer Ther 11: 1770-1780.

54. Park SH, Ryu MH, Ryoo BY (2012) Sorafenib in patients with metastatic gastrointestinal stromal tumors who failed two or more prior tyrosine kinase inhibitors: a phase II study of Korean gastrointestinal stromal tumors study group. Invest New Drugs 30: 2377-2383.

55. Kindler HL, Campbell NP, Wroblewski K, Maki RG (2011) Sorafenib (SOR) in patients (pts) with imatinib (IM) and sunitinib (SU)-resistant (RES) gastrointestinal stromal tumors (GIST): Final results of a University of Chicago Phase II Consortium trial. J ClinOncol 29: 2011.

56. Montemurro M, Gelderblom H, Bitz U (2013) Sorafenib as third- or fourth-line treatment of advanced gastrointestinal stromal tumour and pretreatment including both imatinib and sunitinib, and nilotinib: A retrospective analysis. Eur J Cancer 49: 1027-1031.

57. Kefeli U, Benekli M, Sevinc A (2005) Efficacy of sorafenib in patients with gastrointestinal stromal tumors in the third- or fourth-line treatment: A retrospective multicenter experience. Oncol Lett 6: 605611.

58. Schittenhelm MM, Shiraga S, Schroeder A (2006) Dasatinib (BMS354825), a dual SRC/ABL kinase inhibitor, inhibits the kinase activity of wild-type, juxtamembrane, and activation loop mutant KIT isoforms associated with human malignancies. Cancer Res 66: 473-481.
59. Trent JC, Wathen K, von Mehren M, Samuels BL (2011) A phase II study of dasatinib for patients with imatinib-resistant gastrointestinal stromal tumor (GIST). J ClinOncol 29: 2011

60. Montemurro M, Domont J, Blesius A, Rutkowski P (2012) Dasatinib first-line treatment in gastrointestinal stromal tumors: A multicenter phase II trial of the SAKK (SAKK 56/07). J ClinOncol 30.

61. Soria JC, Massard C, Magne N (2009) Phase 1 dose-escalation study of oral tyrosine kinase inhibitor masitinib in advanced and/or metastatic solid cancers. Eur J Cancer 45: 2333-2341.

62. Le Cesne A, Blay JY, Bui BN (2010) Phase II study of oral masitinibmesilate in imatinib-naive patients with locally advanced or metastatic gastro-intestinal stromal tumour (GIST). Eur J Cancer 46: 1344-1351.

63. (2017) AB Science. A Phase 3 Study to Evaluate Efficacy and Safety of Masitinib in Comparison to Imatinib in Patients With Gastro-Intestinal Stromal Tumour in First Line Medical Treatment.

64. AB Science. A Phase 3 Study to Evaluate Efficacy and Safety of Masitinib in Comparison to Sunitinib in Patients With Gastrointestinal Stromal Tumour After Progression With Imatinib.

65. Ganjoo KN, Villalobos VM, Kamaya A (2014) A multicenter phase II study of pazopanib in patients with advanced gastrointestinal stromal tumors (GIST) following failure of at least imatinib and sunitinib. Ann Oncol 25: 236-240.

66. Benjamin RS, Schoffski P, Hartmann JT (2011) Efficacy and safety of motesanib, an oral inhibitor of VEGF, PDGF, and Kit receptors, in patients with imatinib-resistant gastrointestinal stromal tumors. Cancer Chemother Pharmacol 68: 69-77.

67. Joensuu H, De Braud F, Grignagni G (2011) Vatalanib for metastatic gastrointestinal stromal tumour (GIST) resistant to imatinib: final results of a phase II study. Br J Cancer 104: 1686-1690.

68. Heinrich MC, Corless CL, Blanke CD (2006) Molecular correlates of imatinib resistance in gastrointestinal stromal tumors. J ClinOncol 24: 4764-4774.

\section{Your next submission with Juniper Publishers will reach you the below assets}

- Quality Editorial service

- Swift Peer Review

- Reprints availability

- E-prints Service

- Manuscript Podcast for convenient understanding

- Global attainment for your research

- Manuscript accessibility in different formats

( Pdf, E-pub, Full Text, Audio)

- Unceasing customer service

Track the below URL for one-step submission https://juniperpublishers.com/online-submission.php 